\title{
Paths to improving care of Australian Aboriginal and Torres Strait Islander women following gestational diabetes - CORRIGENDUM
}

\section{Sandra Campbell, Nicolette Roux, Cilla Preece, Eileen Rafter, Bronwyn Davis, Jackie Mein, Jacqueline Boyle, Bronwyn Fredericks and Catherine Chamberlain}

doi: https://doi.org/10.1017/S1463423617000305, Published by Cambridge University Press, 17th July 2017.

First published online 23 October 2017

In the article by Campbell et al. (2017), an important acknowledgement was mistakenly missed off. The authors would like to apologies for this omission. The acknowledgement reads as follows:

'The authors especially thank Professor Kerry Arabena for her valuable guidance in the Project Advisory Group and Investigator team'.

\section{Reference}

Campbell, S., Roux, N., Preece, C., Rafter, E., Davis, B., Mein, J., Boyle, J., Fredericks, B. and Chamberlain, C. 2017 : Paths to improving care of Australian Aboriginal and Torres Strait Islander women following gestational diabetes. Primary Health Care Research and Development, https://doi.org/ 10.1017/S1463423617000305, published online 17th July 2017. 